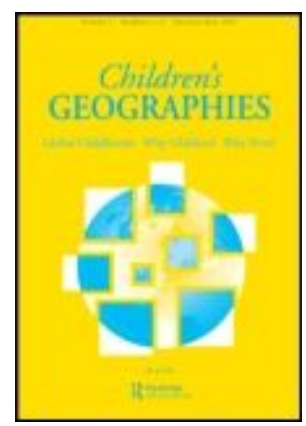

\title{
Muddy Knees or Muddy Needs: Parents Perceptions of Outdoor Learning
}

\begin{tabular}{|r|l|}
\hline Journal: & Children's Geographies \\
\hline Manuscript ID & Draft \\
\hline Manuscript Type: & Original Article \\
\hline Keywords: & $\begin{array}{l}\text { Outdoors, Learning outside the classroom, children's play spaces, } \\
\text { perceptions, Parents voices }\end{array}$ \\
\hline
\end{tabular}

\section{SCHOLARONE \\ Manuscripts}

This is an Accepted Manuscript of an article published by Taylor \& Francis in Children's Geographies on

26/11/2019, available online: http://www.tandfonline.com/10.1080/14733285.2019.1694637 


\section{Muddy Knees and Muddy Needs}

2

3

\section{$4 \quad$ Abstract}

Research highlights that children across the UK access the outdoors less than previous generations, often at levels below that prescribed by the United Nations as a basic level of access for prisoners. School staff and parents are intrinsic partners in facilitating children's access to the outdoors and the associated learning opportunities it presents. There exists however a complex set of relationships and perceptions governing the dynamics of these relationships and the resultant access to opportunities presented by learning outdoors. This paper sought to explore these perceptions by examining data collected through a combination of questionnaires and interviews with parents and teachers. The resultant data highlights a significant disconnect in parent and teacher perceptions related to the purpose, aims and opportunities for learning outdoors. The findings of this study offer implications for early childhood educators, parents and others looking to promote the outdoors as a learning environment across the foundation stage.

\section{Introduction}

\section{The policy context}

Early Years frameworks across the UK are clear in their expectation that children attending early childhood settings should have access to good quality outdoor environments to support development. The Early Years Foundation Stage (EYFS) curriculum for birth to 5 years in England further states that if continuous access is not possible then activities must be 'planned and taken on a daily basis' (EYFS, 2017; 30). The motivation for these recommendations are set amidst growing concern about childhood obesity, with published statistics indicating that one in five children start school overweight (Health and Social Care Information Centre, 2015). Whilst these statistics can be related to several contributing factors, a study by public health England in 2013, clearly links physical exercise with health and well-being. Despite this, the reality for some children is illustrated in research by Berland (2016), his study of over 12,000 families, highlighted that 1 in 10 children never play outdoors. Berland argues that the reason children experience such limited access to the outdoors lay in a combination of factors which include a lack of space to play and the growing use of technology. Berland's research also indicated that $80 \%$ of parents stated that their children preferred to play virtual sports on computer screens than in real life. 
32 A range of individuals and groups essentially act as gatekeepers to children accessing the outdoors and the 33 play opportunities it presents. This paper focuses on the two of the primary gatekeepers, namely schools and 34 parents. A complex relationships and perceptions governing the dynamics of outdoor access and accessibility 35 emerge between these groups. Rothlein and Brett (1987) explored the differing perceptions of outdoor play 36 held by parents, teachers and children between the ages of 2 to 6 years, within an educational setting. Their 37 research established that parents consider outdoor play as fun and part of a child's leisure time and they 38 consider that playtime should be timetabled with dedicated learning taking place in the classroom. These 39 perceptions may well account for a reported reduction of $50 \%$ in unstructured play activities for children over 40 the past decade, demonstrating an increasingly didactic and formalised approach to young children's learning 41 (Almon, 2004). These statistics indicate that many parents increasingly direct children's time at home 42 towards structured, educational activities, centred on academic achievement (Kaiser Family Foundation, 43 2005). What is emerging therefore is a clear dichotomy between what play is and what play is for; and how 44 such activity is best enabled to support the holistic educational development of children. Consequently, 45 researchers such as Jayasuriya et al. (2016) call for improved communication between schools and parents. 46 Such communication they argue will make clear the pedagogy of outdoor teaching and learning methods, 47 aims and goals will therefore be known and understood.

Jarvis et al. (2014) argues that the increased focus on school readiness may further contribute to a reduction in time for outdoor play in early childhood educational settings. However, the phenomenon has been attributed to several factors including: parental preference for structured activities, expansion in technology, parent's fears associated with children's safety, concerns related to the weather and the rise of the indoor lifestyle of adults (Frost, 2009; Gleave, 2009; Little, 2015). Frost (2009) further warns of the detrimental effects that continued restriction of children engaging in outdoor play on children's mental health, physical health, creative thinking and low appreciation and investment in the natural environment.

\section{The benefits of learning outdoors}

The benefits of outdoor education have been argued for some time, with links to reductions in obesity rates (1) (Milteer and Ginsburg, 2012), improved mental health (Knight, 2013) and improved cognitive and 60 behavioural development (Dillon et al., 2005). Research indicates that learning outdoors enables children to experience complex and unique experiences that provide a range of opportunities, including physical challenges, opportunities for exploration, constructive play and social and dramatic play. The physical activity 63 facilitated by unstructured outdoor play sessions has also been shown to promote a healthier lifestyle in later 64 life and thus lower the risk of future health issues. Additionally commentators such as White and Woolley 65 (2014) argue that the outdoors is an exceptional environment for the play-based learning advocated by the Early Years Foundation Stage (EYFS) (DfE, 2017). Why and how the outdoors offers such a successful learning 
67 environment may be explained by Kaplan and Kaplan's Attention Theory (1984) which argues that children 68 have a much improved focus after spending time outdoors in the natural environment. This theory aligns 69 with Wilson's (1984) work which detailed the Biophilia hypothesis that draws strong links between the 70 natural environment and human beings, arguing the existence of an instinctive and innate relationship with 71 the natural world.

Exploration, physical activity and risk are central to a child's development (Knight, 2015). Societal fear of risk is deemed as one of the major factors which has contributed to the decline in outdoor play and learning (Sutton, 2008). This decline was highlighted by England Marketing (2009), who reported that $40 \%$ of adults played in their natural environment as children, compared to less than $10 \%$ of children today. Louv (2011), in considering the overall decline of children accessing the outdoors, suggested that children and adults may suffer from a Nature Deficit Disorder. Louv considers this phenomena a direct result of reduced access to the outdoors, provoked by a culture of fear that lay behind the tendency to choose organised indoor play (Sutton, 2008). Louv (2011) further describes the human costs of alienation from the natural world, suggesting that this can lead to a suite of behavioural issues.

The problem rests therefore, not in the lack of opportunity but in the lack of understanding and knowledge related to how and why the outdoors should be utilised as an environment for learning. Dyment and Coleman (2012) agree, arguing that the outdoors is under recognised as a rich resource for learning, the reason for this they state is multifaceted and partly due to practitioner's reluctance and lack of training in how to use the outdoors to facilitate learning experiences for children (Bilton, 2014a). A lack of confidence in practitioners may also be attributed to the lack of control that can be experienced in the outdoors when compared to a classroom. Indeed Ceppi and Zini (1998) propose that while the indoors is a controlled and quantified territory; the outside may be the optimum learning environment but one in which practitioners lack control. This view concurs with research from Dillon et al. (2007), which identified a pedagogical barrier, whilst teachers felt the ownership and control in the indoor classroom space, once outside the time and space was owned by pupils.

The reluctance of practitioners to utilise the outdoors as a learning environment pervades. Practitioners blame a shortage of time, brought about by a growing culture of accountability combined with the growing pressure for academic attainment from both parents and government (Maynard, 2007). The EYFS (2017) highlights how outdoor environments that are rich in resources and activities can significantly benefit learning in the early years. However, it neglects to highlight and delineate the differences between an outdoor classroom and learning outdoors, with the first being simply a replication of the indoor environment and making little use of the opportunities to interact and learn from nature and the opportunities it presents. 
It is further argued that the advantages and disadvantages of open door access to the outside versus a structured, timetabled or restricted access policy is poorly understood (Whitbread and Bingham, 2014). It would appear therefore that the implementation of the EYFS has become more concerned with school readiness than its stated goals and that this has left practitioners confused between supporting play and preparing the child for a journey through to school.

\section{Parents-teacher perceptions and views}

The effectiveness of outdoor play based experiences as an approach for learning is still a relatively new concept to many parents (Fisher et al., 2008), concurring with Sigel and McGillicuddy-De Lisi (2002) who suggest that parents' beliefs about their child's education develop from their own cultural and educational experiences. Interestingly, Rouse (2015) concluded that parents' perceptions of the effectiveness and types of learning that their child encounters outdoors are often misunderstood. Rouse (2015) proposes that information on the aims of outdoor play is not well communicated to parents and as a result the overall benefits and goals of an outdoor play-based learning approach are not widely acknowledged. Rouse (2015) further argues that, despite parents and teachers considering themselves as working in partnership to secure the best outcomes for children, when questioned parents were unable to articulate the benefits of what their child had been achieving outdoors. Research has found that there are significant benefits to engage in staff/parent participation (Gonzalez and Jackson, 2013; Sad and Gurbuzturk, 2013) as both have a vested interest in children's development and share common goals. In particular, a study by Jayasuriya et al. (2016) explored parent's perceptions of outdoor activity in a pre-school setting. They identified that ensuring parents had a full understanding of their child's educational journey delivered significant benefits in terms of parental participation and understanding, arguing that parents need to understand the pedagogical influences that underpin the schools' ethos.

The argument that parents prefer goal orientated and timetabled play was explored by Jensen (2002) in a cross-cultural study of parental attitudes. Jensen's data indicated that this was not due to parental misunderstanding of the value of play but more that parents perceived structured and scheduled activities better prepared children for the demands of later life. However, Ailwood's (2003) research dismissed this belief, arguing that even if children's play was planned with timetabled access, it can restrict freedom of choice for the child. This, Ailwood argues, can lead to a restriction of potential learning opportunities and subsequently the development of independent thinking.

Teachers may often act as gatekeepers, shaping the participation opportunities that parents have in their child's education (Karila and Alasuutari, 2012). However, Fleer (1995) suggests that parents should be equally intrinsic in realising children's potential educational outcomes. Moreover, Karila and Alasuutari suggest that 
this partnership should have constructive common goals for the child's development. Braun (1992) suggests that whilst parents have the right and responsibility to choose what they feel is best for their child, some do not possess the confidence and knowledge to make informed decisions concerning appropriate teaching and learning approaches. As such, commentators such as Stipek et al. (1992) argue that appropriate parental education is necessary to equip parents to make well informed decisions concerning how to support their developing child. However, Desforges and Abouchaar (2003) and Hadley (2012) suggest that in reality there is still a lack of communication between teachers and parents, despite education policy, including the EYFS, which indicates the value of parent-teacher partnerships. Ball (1994) identifies that school-parent communication can be impacted negatively by pre-existing power relationships and argues that if parents are to be considered an intrinsic part of their child's education it is important that the voices of all parents are heard and engaged with.

This paper explores the extent to which parents perceive the outdoors as an environment for learning in the EYFS and additionally explores the level to which they identify the potential benefits of providing such opportunities. Furthermore, the paper explores the differences and synergies between parent's views and how these map to those of teachers.

\section{Methodology}

The school playground can be perceived a daunting place for the most confident individual, with both parents and children at times bowing to the pressure of an invisible hierarchy and undercurrent of playground ethics (Wilson, 2013). The language of a playground is one of opinions, praise, support and at times negativity and can often become a catalyst for success, failure and change (Blackford, 2004). The hidden pressure to conform to the expressed opinions of playground hierarchy is one that parents frequently encounter. The research was therefore mindful of the research environment and the necessity to afford space to parents to formulate their own responses and relate their individual experiences.

The sample utilised an opportunity sample approach and staff and parents who accessed or worked in the provision were invited to participate. The sample included 16 parent respondents, 12 female and 4 male aged between 28 and 41 from a largely white, middle class background and two members of staff including a teacher and teaching assistant. The data collection methods were designed to assess and examine parental views on children's access to outdoor play based learning opportunities and determine if parents were aware of the purpose and aims of such experiences. Both quantitative and qualitative approaches were utilised through self-completing questionnaires and targeted interviews. The research adopted a subjective 

60

constructivist approach to the design and analysis of the data. Each parent offered responses based on their own perspective of outdoor play and their own individual child or children.

The research took place in an average sized, semi-rural, local authority run primary school in the North of England (OFSTED, 2015). The school has a Free School Meals (FSM) quota and Pupil Premium which is significantly below national average (OFSTED, 2015). However, the school accommodates the national average of children with Special Educational Needs and Disability (SEND). This study focussed on provision for children in the Foundation stage (FS). The FS unit currently accommodates 32 FS students split between two classrooms, one of which houses 26 FS 1 children (aged 3-4) and a further classroom housing 20 Yr. 1 children and 6 FS 2 children (aged 4-5). Both of these classrooms have access to the dedicated outdoor foundation stage area. The study invited all parents of children in the foundation stage classrooms to participate.

The questionnaire collected both quantitative and qualitative data through a series of semi structured and multiple choice questions. The questionnaire was distributed to all parents of the 32 children in the foundation stage and 16 agreed to participate in the study. The questionnaire was distributed to parents via their children and accompanying letters of consent and information were provided to ensure that ethical considerations were observed. The questionnaire was returned via a stamped addressed envelope attached to the document, this both preserved anonymity and ensured a maximum return (Bryman, 2012).

In addition to the questionnaire, interviews were conducted with the staff within the setting at times convenient to themselves, each interview engaged the respondent for thirty minutes. The interviews took place on a one to one basis and were conducted within the school environment with pre-determined open ended questions. These questions were created and designed to complement and contrast the questionnaire completed by parents as part of the study. The interviews were digitally recorded and transcribed for further analysis.

\section{Approach to Data Analysis}

The data derived from the questionnaires were analysed using thematic analysis in combination with some statistical analysis of data from multiple choice questions. The multiple choice questions included five possible answers to each question; statistics were used to determine if there were any significant trends or responses within each set of questions. The questionnaire also provided opportunity for participants to contribute additional comments by the inclusion of open ended semi structured questions, these contributions ensured that the data reflected both validity and reliability. The graphical and statistical results 
were analysed alongside the detailed qualitative responses, providing a holistic analysis which utilised both overarching data from the questionnaires and the interviews.

The sorting, coding and analysis of qualitative data was undertaken at several levels to form constructs. Initially labels were low inference and descriptive, staying close to the data. The first level of analysis was undertaken through highlighting, making notes and mapping to determine the respondents' beliefs and feelings. Hand coding was utilised for this purpose. This facilitated familiarisation with the data and facilitated the formation of codes and themes. Themes identified related to weather, time, clothing and attitudes and beliefs.

\section{Results and Discussion}

This section reviews and analyses the findings from the combined data sets and reflects on the research question and the context for the results. The findings were critically synthesized alongside a range of previous research addressing the overall aim of the work, which was to identify parents' perspectives of the benefits of children having access to the outdoors. Furthermore, the paper sought to determine parent's understanding and appreciation of the use of outdoor play based learning in children's education, achievement, health and wellbeing.

\section{The question of time}

The results presented herein highlighted that participants (the parents) considered the outdoors as equal to the indoor classroom in terms of providing an effective learning environment. A total of $75 \%$ of parents believed that their children always $(56 \%)$ or often $(19 \%)$ learn on an equal measurement in either environment. Critically however, the analysis of the contextual comments revealed that parents consider both environments equally beneficial as long as the time children spent outdoors is structured and adult led. Illustrated by one respondents comment below:

"Depends on the topic and if adult led and depends whether they are being taught or free play, sometimes I think they are not mature enough to play together without adult intervention"

Such comments highlight that many parents, although recognising some of the benefits of outdoor play, are unable to appreciate the specific benefits of learning outdoors, which by default, reflect the strategic aims of the EYFS. 
The results also highlight that the time parents believe their children should, and do, spend outdoors when at school is a further misconception. The results reported herein indicate that parents perceived a necessity for limited time in the outdoors for their children (Figure 1).

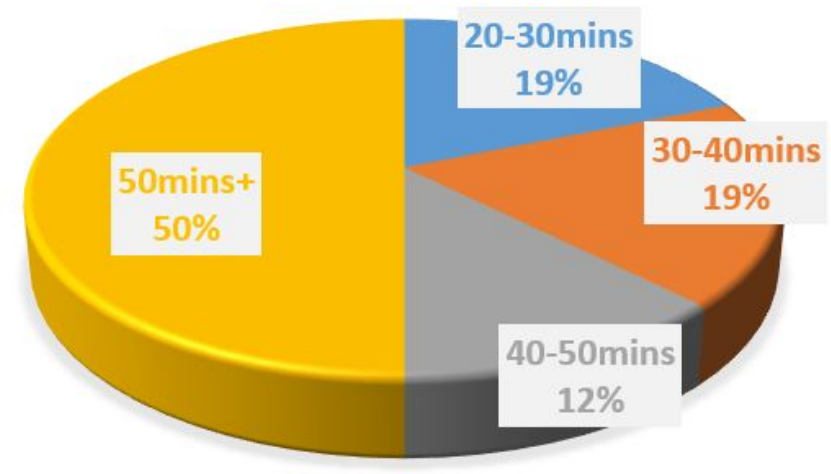

Figure 1: Reported time (in minutes) that respondents thought children should play outdoors

Figure 1 highlights that 50\% of parents in the study considered that less than 50 minutes in the outdoor environment per day was an appropriate allocation of time for outdoor play and learning. When asked how many times a day children should access the outdoors, 70\% of the parents offered responses indicating 3 times a day would be acceptable, with contextual comments suggesting that this mapped to two breaks and lunchtime. However, when asked if their child enjoyed playing outdoors, parents acknowledged there appeared to be a strong connection for the vast majority of children with the outdoors, with $88 \%$ saying that they always (75\%) or often (13\%) enjoyed outdoor play. These results suggest that the parents in this study appear to apply some value to the outdoors as a learning environment, yet do acknowledging it as an enjoyable leisure activity for their children.

The results also reveal a distinct gender bias in relation to perceived access to the outdoor environment and appropriate lengths of time parents thought their children should spend in the outdoors. Table 1 below demonstrates that parents of boys report more regular access to outdoor activity (significant at the 95\% confidence level $(p=0.034)$. Moreover, the length of time parents thought appropriate for children to play outside also had a distinctive gender bias, with parents of boys allocating and suggesting a need for more time to be spent outside. Staff also articulated a gender bias in their separate interviews, with teachers suggesting that more boys than girls access the outdoors. A significant volume of research exists on gender differences in education (Anderson, 2012; Bilton, 2014b; Chapman, 2015; Sandseter, 2014), yet very little research has been conducted related to gender and access to learning outdoors in educational contexts, indicating a clear gap in the literature worthy of further investigation. 
Table1: Proportions of children who are reported to play outside in response to question 1 in the survey The table highlights the gender of the participant's child (M) Male (F) Female

\begin{tabular}{|c|c|c|c|c|c|}
\hline & Always & Often & Sometimes & Occasionally & Never \\
\hline Person 1 (M) & & $\mathrm{x}$ & & & \\
\hline Person 2 (F) & & & $x$ & & \\
\hline Person 3 (F) & & & $x$ & & \\
\hline Person 4 (M) & $x$ & & & & \\
\hline Person 5 (M) & & $x$ & & & \\
\hline Person 6 (M) & & $x$ & & & \\
\hline Person 7 (F) & & & & $x$ & \\
\hline Person 8 (M) & & $\mathrm{x}$ & & & \\
\hline Person 9 (F) & & $x$ & & & \\
\hline Person 10 (F) & & $\mathrm{x}$ & & & \\
\hline Person 11 (F) & & & $x$ & & \\
\hline Person $12(\mathrm{M})$ & $\mathrm{X}$ & & & & \\
\hline Person 13 (F) & & $\mathrm{x}$ & & & \\
\hline Person 14 (M) & & $x$ & & & \\
\hline Person 15 (M) & & $x$ & & & \\
\hline Person 16 (F) & & $x$ & & & \\
\hline
\end{tabular}

The contextual comments in the questionnaires also highlighted that many parents were additionally unaware of school policies relating to children's rights in terms of access the outdoors. Furthermore, responses from the staff confirmed that whilst many parents demonstrate an understanding of how their children learn, they appeared less knowledgeable in relation school's aims notably in relation to outdoor play and learning. It could be argued what appears to be a fundamental lack of understanding may be partly explained by a lack of communication between school and parent. These assumptions are supported in research by Rouse (2015), who argued that not only were the aims of learning outdoors not well communicated to parents, but teachers lack of confidence and training in relation to learning opportunities outdoors resulted in a lack of confidence to communicate with parents on the provision. Subsequently a lack of cooperation and communication between the school leadership team and parents could lead to decreased opportunities for free access to the outdoors within the school day and a lack of appropriate clothing and resources provided by parents in order to enable this.

\section{Whatever the weather we are out there together}

A further factor which appeared to mitigate against children's opportunities to learn outdoors was the weather. The data indicated that inclement weather was mentioned multiple times as a reason to restrict access to the outdoor environment. Research by Ridgers et al. (2015), concurred, arguing that outdoor learning was very much confined to the milder weather of the summer season. A minority of the contextual comments offered by parents concur with Ridger's findings. These responses are exemplified by the responses from two parents who commented; 
"Depends on the weather, if it's cold and miserable then so is the child"

And, a further response arguing that:

"when they (children) are cold/wet and forced to go outside they then spend the rest of the day cold and wet and cannot concentrate.

However, these responses were less common in the overall data. Research by Jayasuriya et al. (2016) revealed similar findings suggesting that only a minority of parents reported that they did not want their child to play outside in less favourable weather. Overall the data suggested that parents viewed outdoor activity as a 'good thing' and that they understood the value of engagement in outdoor learning. These responses are argued by Mycock (2018) to be synonymous with a trend of middle class parental constructs which identify children becoming dirty through play as a re wilding of childhood, a sign of free wholesome and happy children. It could be argued that such attitudes are the privilege of the middle classes who have the resources and social capital to embrace the opportunities presented by activities accessed outdoors, without the worry of the stigma of neglect or poverty which may be related to children wearing muddy dirty clothes (Mycock, 2018).

Issues concerning appropriate clothing for the outdoors could reasonably be mitigated against through the provision of protective clothing for all and/or effective communication of what constitutes appropriate clothing for the outdoor conditions. However, Hatcher and Squibb (2011) suggest that even if parents are aware of the need for appropriate outdoor clothing, there may be significant time needed for staff to prepare children for outdoor play and that this can still present a barrier to its effective implementation. Hatcher and Squibb (2011) do nonetheless highlight, that the time utilised preparing children to be outdoors can provide valuable opportunities for adult and child interaction, aiding communication, personal, social and emotional development and physical skills that would not routinely have been addressed in a normal indoor learning context. The interviews with the staff confirmed that most parents were untroubled by their children getting wet and muddy at school, though they warned that one or two parents became "quite upset" when the occurrence arose. Whilst these parents may represent a minority, Copeland et al. (2012) warns that even a few parents who do not support outdoor play in light rain or cold temperatures can hinder entire classrooms accessing the outdoors. This perceived reluctance was successfully mitigated against in studies by both Copeland et al. (2009) and Dwyer et al. (2008) who evidenced that by better informing parents of school policy, and guidance related to outdoor play and its benefits, parental participation and willingness to better prepare their child for play and learning outdoors was raised. 


\section{Parental understanding of the benefit of outdoor play}

The results reported in this paper highlight that a minority of parents misunderstand the structure, purpose and benefit of outdoor play-based learning opportunities. The benefits of accessing the outdoors are well known. Physical activity is beneficial for children's health (Louv, 2011; Biddle et al. 2004) and is also key for various aspects of learning, cognition (Kaplan and Kaplan, 1989), and well-being (Becker et al. 2014). Outdoor play is additionally argued to foster social-emotional and cognitive development through problem-solving skills and creativity-based activities (Harte, 2013). Despite these known benefits and recommendations, a range of studies now highlight that some parents tend to be unaware of the aims or value of outdoor play (Mycock, 2018,: Jayasuriya et al., 2016,: Rouse, 2015). The results in this study indicate that parents are mindful and appreciative of the opportunities for the social and physical development of the child. However, two parents struggled to see the value for the academic development of their child. Responses from one respondent illustrated this argument as she argued:

'Outdoor play is essential for the physical and social aspects in life. Outdoor play can be rougher and very much harder as that of a classroom situation, a child is more likely to be themselves as opposed to being how they need to be to learn'.

With a further comment adding that:

'It depends on the activity and learning objectives of the lesson, the teachers and teaching style, it (outdoor play) should be linked to their learning and structured'.

These views could result from the question being perceived by the participant differently to that intended. As indicated by (Denscombe, 2014) one of the weaknesses of a self-completion questionnaire is the lack of availability of the researcher to clarify the question. However, one interpretation is that the comments are most likely attributable to some parents not fully understanding what the outdoor environment can facilitate in terms of learning experiences.

Indeed, the responses from the staff indicated that some parents are aware of the benefits or use of the outdoor environment as a place of enquiry and learning but do not always recognise the opportunities for academic learning that may result from engaging in outdoor play, as illustrated in the following exert from the interview with the teacher:

'Our parents are very well educated, I think they do see the value in it but I also think that in terms of erm... the academic stuff, they think that can only be done inside...'

Further commenting: 
'They believe if they play outside they are having a really nice time at school, rather than learning out there.'

The responses above support an argument that parents are perceiving the indoor environment as not providing for more "academic" learning and acquisition of skills. Almon (2004), concurs, proposing that data in his study indicates that parents prefer their children to play and learn in structured environments. This paper argues that such perceptions may well arise from parents' experiences and histories which impact on their understanding of how to best prepare children for the future (Mycock, 2018). Fisher et al. (2008) concurs, arguing that the notion of play-based learning outdoors is a relatively new concept for parents and not an educational approach they would have encountered in their own education. As such, parents have a pre-determined set of ideas based on their experiences and resultant cultural expectations of education and views on what constitutes effective learning (Mycock, 2018). Cultural expectations will only change through the education of individuals involved in order to equip them with the understanding of the benefits such experiences can bring.

In order to understand why parents develop the understanding and the value they place on outdoor experiences for their child's learning, it is necessary to consider the culture and political context within which the data arises. The rising pressure from government through standardized testing and the concern from both parents and teachers that children need to reach increasingly unrealistic targets to become academically successful, has generated concern (TACTYC, 2018). This paper argues that there is evidence for a rethink of the trend toward prescribed academic learning above autonomous problem-based learning. Evidence for the effectiveness of such approaches can be drawn from the work of academics such as Canning (2007), who suggests that when children take part in unstructured play opportunities, their ability to take part in the process of inquiry based learning can grow. When a child is left alone to solve problems and experiment with their ideas with no predetermined targets, they are developing core schemas (Athey, 1990, Atherton and Nutbrown, 2013). Unstructured play opportunities outdoors can additionally provide opportunities for peer supported learning to take place (Atherton and Nutbrown, 2013). These understandings were well illustrated by the contextual comments from the teacher who stated:

'Some boys that spent every single day outside, they would come and do their focused activity with an adult but then they would go straight back outside... erm... and they achieved the same if not better than some of the girls who chose to stay inside'.

And a further response offered by the teaching assistant:

'The majority of boys would play outside.... Amazed I think we were shocked how much they had taken in as when they were sat on the carpet they would listen...' 


\section{No such thing as bad weather, just inappropriate clothing}

A further barrier to outdoor play and learning appeared to manifest in concerns related to protective clothing to guard against the weather and dirt. Whilst parents articulated an understanding that there was a need for children to be outdoors in all weathers, they were keen to add that appropriate clothing had to be a prerequisite to the activity. One parent illustrates this concern in her response as she states:

'With appropriate clothing, I object to their shoes being covered in mud when they have wellies at school. Being told they cannot wear wellies to school as there is no space to store them, only shoes is unacceptable!

Indeed parents in this context appeared to articulate strong but positive views:

'They should be out as much as possible but not if they are not dressed appropriately for the weather. Schools could have a donated outdoor clothes box that children could access if they are cold. In the UK it is not always possible to dress your child in the morning for the weather in the afternoon. Therefore, having access to appropriate clothing for each play session would be good. I think as much teaching should be done outside as possible - not just Forest School for Foundation.'

Data collected from Parent's questionnaires concerning the times when their child came home muddy or wet indicated that $44 \%$ reported it was a common occurrence. As such it seems that a clear barrier to the parents being happy about children accessing the outdoors seems to relate to communication about the need to provide appropriate clothing from home and the schools ability to provide such resources. There appears then to exist a clear disconnect between parental and staff understanding of availability of resources and the parental responsibility to ensure that their child is adequately prepared. Staff having confirmed that protective clothing was available acknowledged that children do regularly get dirty and wet despite resources being available, as one participant confirmed:

'They get dirty all the time...they tend to play in the mud kitchen more in the winter because its more soupy and they can make more with it rather than when it's hard. When it's wet out there they will gravitate to the wet and the mud.'

The school staff stated that they are understanding about dirty footwear and clothing and pressure is not placed on parents to ensure that clothing is clean and mud free on a daily basis. However, Mycock (2018) points out that social pressures on parents related to the presentation of their child at school are likely influences on parent's reluctance to accept the challenge of muddy clothing and shoes.

Although several studies have considered teacher and provider perspectives in support for the need for outdoor active play facilitation (e.g. Copeland et al., 2009; Gehris et al., 2015). Only Jayasuriya et al. (2016) 
and Mycock (2018) have recently begun to explore parent's perceptions of outdoor learning, demonstrating a potential lack of research in the area. Parents are a critical component for supporting children's early development, as such parent partnerships have a profound effect on a child's education (OECD starting strong II, 2006). Indeed, the EYFS states that parent participation, communication and consultation is seen as a priority (DfE, 2017). Jayasuriya et al. (2016) highlight that the dialogue between childcare providers and parents around the many benefits of outdoor play opportunities could increase both groups' value of outdoor play. This paper suggests that improvements in communication could include more comprehensive written information, displays and conversations during parent-teacher meetings. This paper concludes that parents should be included in conversations about the activity around learning outdoors, including preparing and dressing for differing weather conditions, practice and behaviours at home as well as at school..

\section{Conclusion}

The benefits of learning outdoors are known and are well supported by a range of studies. National strategies and policies are in place that are attempting to foster and encourage the use of outdoor learning across the sector in the UK. However, this paper reveals a number of barriers to effective implementation of these policies, these barriers revolve around, time, assessment targets, access and staff and parental confidence and knowledge. The complex and multifaceted relationship between policy, school/teacher and ultimately parent's perceptions are all key elements within the related discourse.

This paper has highlighted that there are significant issues concerning parent-teacher communication and outdoor play based learning. The findings have potential implications for early childhood educators and others interested in providing and promoting outdoor play-based learning opportunities across the foundation stages. Parents are supportive of the outdoors but there remains clear misinterpretation on play and learning outcomes from some respondents. The research further highlights that from a parents perspective there are barriers to outdoor play primarily concerned with the weather and appropriate clothing and how and if these are utilised by the school. Limited communication related to the objectives of learning outdoors, the amount of time children should and do spend outdoors and the school policies which guide practice, all contribute to evidence for more effective parent-teacher communication and fuller partnership engagement between the two parties.

This paper argues that where concerns are raised, additional dissemination of information to parents concerning the clear benefits of outdoor activities for health, social and emotional wellbeing and cognitive development is desirable. Encouraging parent-teacher communication could lead to clearly articulated strategies which could promote active learning opportunities for children in the outdoors. Working collaboratively together enables teachers and parents to contribute to the effective realisation of these ambitions. 


\section{REFERENCES}

Ailwood, J. (2003). Governing early childhood education through play. Contemporary Issues in Early Childhood, 4(3), 286-298. Almon, J. (2004) The vital role of play in childhood. Chestnut Ridge, New York: Waldorf Early Childhood Association of North America.

Anderson, M.L., 2012. Multiple inference and gender differences in the effects of early intervention: A reevaluation of the Abecedarian, Perry Preschool, and Early Training Projects. Journal of the American Statistical Association.

Atherton, F and Nutbrown, C. (2013), Understanding Schemas and Young Children, London, Sage

Athey, C. (1990) Extending Thought in Young Children: A Parent-Teacher Partnership. London: Paul Chapman

Ball, C. (1994) Start Right: the importance of early learning. London: RSA.

Becker, D. R., McClelland, M. M., Loprinzi, P., and Trost, S. G. (2014) Physical activity, self-regulation, and early academic achievement in preschool children. Early Education and Development, 25 (1), pp.5670.

Berland, E., (2016) Dirt is Good. Unilever

Biddle, S. J., Gorely, T., and Stensel, D. J. (2004) Health-enhancing physical activity and sedentary behaviour in children and adolescents. Journal of Sports Sciences, 22 (8), pp.679-701

Bilton, H. (2014a). What is outside? The Early Years Foundation Stage in England: Outdoor Facilities, Organisation and Staff Attitudes. American Journal of Educational Research. 2 (10), 942-949.

Bilton, H., (2014b) The Aims of Early Years Outdoor Education in England: a Conceptual and Empirical investigation. University of Reading.

Blackford, H. (2004) Playground Panopticism: Ring-around-the-children, a pocketful of women. Childhood, $11(2)$, pp. 227-249.

Braun, D. (1992). Working with parents. In G. Pugh (Ed.), Contemporary Issues in Early Education (pp. 175190). London, England: Paul Chapman Publishing.

Bryman, A. (2012) Social Research Methods. Oxford: Oxford University Press.

Canning, N. (2007). Children's empowerment in play. European Early Childhood Education Research Journal, 15 (2), pp227-236.

Ceppi, G., and Zini, M. (1998). Children, Spaces, Relations: Metaproject for an Environment for Young Children. Reggio Children, Piazza della Vittoria, 6, 42100, Reggio Emilia, Italy.

Chapman, R., (2015) A case study of gendered play in preschools: how early childhood educators' perceptions of gender influence children's play. Early Child Development and Care, pp.1-14.

Childhood Obesity Plan (2017): A plan for action, accessed on 27/02/2019 Available at: www.gov.uk/government/publications/childhood-obesity-a-plan-for-action/childhood- obesity-aplan-for-action

Copeland, K., Kendeigh, C., Saelens, B., Kalkwarf, H., Sherman, S. (2012). Physical activity in child-care centers: do teachers hold the key to the playground?. Health Educ Res, 27 (1), pp. 81-100. 
Denscombe, M. (2014). The good research guide: for small-scale social research projects. McGraw-Hill Education (UK). Open University Press.

Desforges C., and Abouchaar, A. (2003) The Impact of Parental Involvement. Parental Support and Family Education on Pupil Achievement and Adjustment: a Literature Review, RR 433

Dillon, J., Morris, M., O’Donnell, L., Reid, A., Rickinson, M., and Scott, W. (2005) Engaging and learning with the outdoors: the final report of the classroom in a rural context action research project. Berkshire: National foundation for educational research.

Dwyer, M.C., Chait, R. and McKee, P. (2008) Building Strong Foundations for early learning; the US Department of Education's guide to high quality childhood education programs. Washington DC : US Department of Education

Dyment, J. and Coleman, B. (2012) The intersection of physical activity opportunities and the role of early childhood educators during outdoor play: Perceptions and reality. Australasian Journal of Early Childhood. 37 (1), pp. 90-98.

England Marketing (2009) Report to Natural England on Childhood and Nature: A survey on changing relationship's with nature across generations.

EYFS, Department of Education (DfE) (2017). The Early Years Foundation Stage (EYFS), London: Department of Education.

Fisher, K.R., Hirsh-Pasek, K., Golinkoff, R.M. and Gryfe, S.G., 2008. Conceptual split? Parents' and experts' perceptions of play in the 21st century. Journal of Applied Developmental Psychology, 29 (4), pp.305-316.

Fleer, M. (Ed.). (1995). DAPcentrism: Challenging developmentally appropriate practice. Watson, ACT: Australian Early Childhood Association. Frost, J.L. (2009). Back to nature and the emerging child saving movement: Restoring children's outdoor play. Children and Nature Network Writing Series, $1(3), 1-13$.

Gehris, J., Gooze, R., Whitaker, R. (2015). Teachers' perceptions about children's movement and learning in early child education programmes. Child: care, health and development,

Gleave, J. (2009). Children's time to play: A literature review. London: Play England.

Gonzalez, R. L., and Jackson, C. L. (2013) Engaging with parents: The relationship between school engagement efforts, social class, and learning. School Effectiveness and School Improvement, 24 (3), pp.316-335.

Hadley, F. (2012). Early childhood staff and families' perceptions: Diverse views about important experiences for children aged 3-5 years in early childhood settings. Contemporary Issues in Early Childhood, 13(1), 38-48. Harte, H. A. (2013) Universal design and outdoor learning. Dimensions of Early Childhood, 41 (3), pp.18-22.

Hatcher and Squibb (2011) Going Outside in Winter: A Qualitative Study of Preschool Dressing Routines, Early Childhood Education Journal 38 (5):pp. 339-347.

Jarvis, P., Newman, S., and Swiniarski, L. (2014) On 'becoming social': the importance of collaborative free play in childhood. International Journal of Play, 3 (1), pp.53-68.

Jayasuriya, A., Williams, M., Edwards, T. and Tandon, P., (2016) Parents' Perceptions of Preschool Activities: Exploring Outdoor Play. Early Education and Development, pp.1-14. 
Jensen, A. F. (2002). Time for playful learning? A cross-cultural study of parental values and attitudes towards children's time for play. Billund, Denmark: Lego Learning Institute.

Kaiser Family Foundation (2005). A teacher in the living room? Educational media for babies, toddlers and preschoolers. Menio Park, California: Kaiser Family Foundation.

Kaplan, R and Kaplan, S. (1989) The experience of nature. A psychological perspective. Cambridge: Cambridge University Press

Karila, K., \& Alasuutari, M. (2012). Drawing Partnership on Paper: How do the Forms for Individual Educational Plans Frame Parent-Teacher Relationship? International Journal about Parents in Education, 6 (1), 15-27.

Knight, S. (2015). Forest School in the United Kingdom. London, Routledge International Handbook of Outdoor Studies.

Little, H. (2015) Mothers' beliefs about risk and risk-taking in children's outdoor play, Journal of Adventure Education and Outdoor Learning, 15(1).

Louv, R. (2011) The nature principle: Human restoration and the end of nature-deficit disorder. Chapel Hill: Algonquin Books of Chapel Hill.

Maynard, T. (2007) Encounters with Forest School and Foucault: a risky business? Education 3-13, International Journal of Primary, Elementary and Early Years Education, 35 (4), pp. 379-391.

Milteer, R. M., Ginsburg, K (2012). The importance of play in promoting healthy child development and maintaining strong parent-child bond: focus on children in poverty. Pediatrics, 129 (1), pp. 204-213.

Mycock, (2018)

OFSTED (2018) Inspection report, file:///C:/Users/Katie/Downloads/1178662\%20(1).PDF (Accessed 08.03.2016)

Ridgers N.D., Salmon, J., and Timperio, A. (2015) Too hot to move? Objectively assessed seasonal changes in Australian children's physical activity, International Journal of Behavioral Nutrition and Physical Activity DOI: 10.1186/s12966-015-0245

Rothlein, L., and Brett, A. (1987). Children's, teachers and parents' perceptions of play. Early Research Quarterly, 2 (1), pp.45-53.

Rouse (2015) Making learning visible - parents perceptions of children's learning outdoors, Early Child Development and Care, 186 (4)

Şad, S., and Gurbuzturk, O. (2013) Primary school students' parents' level of involvement into their children's education. Educational Sciences: Theory and Practice, 13 (2), pp. 1006-1011.

Sandseter, E.B.H., (2014) Early childhood education and care practitioners' perceptions of children's risky play; examining the influence of personality and gender. Early child development and care, 184 (3), pp.434-449.

Sigel, I. E., McGillicuddy-DeLisi, A. V., \& Goodnow, J. J. (Eds.). (1992). Parental belief systems: The psychological consequences for children (2nd ed.). Hillsdale, NJ, US: Lawrence Erlbaum Associates, Inc.Stipek, D., Milburn, S., Clements, D., and Daniels, D. H. (1992). Parents' beliefs about appropriate education for young children. Journal of Applied Developmental Psychology, 13(3), 293- 310. 
Sutton, L. (2008). The state of play: Disadvantage, play and children's well-being. Social policy and society, 7 (04), pp.537-549.

White, J. and Woolley, H. (2014). What makes a good outdoor environment for young children? In: Maynard, T and Waters, J. Exploring Play in the Early Years, Berkshire: Open University Press.

Whitebread, D. \& Bingham, S. (2014). School readiness, starting age, cohorts and transitions in the early years. In J. Moyles, J. Payler \& J. Georgeson (Eds.). Early Years Foundations: Critical Issues, 2nd Ed. (pp. 179-190). Maidenhead: Open University Press.

Wilson, E.O. (1984) Biophilia. Cambridge: Harvard University Press.

Wilson, H, F. (2013) Collective life: parents, playground encounters and the multicultural city, Social and Cultural Geography, 14 (6), pp. 625-648. 
Table1: Proportions of children who are reported to play outside in response to question 1 in the survey The table highlights the gender of the participant's child (M) Male (F) Female

\begin{tabular}{|c|c|c|c|c|c|}
\hline & Always & Often & Sometimes & Occasionally & Never \\
\hline Person 1 (M) & & $\mathrm{X}$ & & & \\
\hline Person 2 (F) & & & $x$ & & \\
\hline Person $3(\mathrm{~F})$ & & & $x$ & & \\
\hline Person 4 (M) & $x$ & & & & \\
\hline Person 5 (M) & & $\mathrm{x}$ & & & \\
\hline Person 6 (M) & & $x$ & & & \\
\hline Person 7 (F) & & & & $\mathrm{X}$ & \\
\hline Person 8 (M) & & $x$ & & & \\
\hline Person 9 (F) & & $x$ & & & \\
\hline Person 10 (F) & & $x$ & & & \\
\hline Person 11 (F) & & & $x$ & & \\
\hline Person 12 (M) & $x$ & & & & \\
\hline Person 13 (F) & & $\mathrm{X}$ & & & \\
\hline Person 14 (M) & & $x$ & & & \\
\hline Person 15 (M) & & $x$ & & & \\
\hline Person 16 (F) & & $x$ & & & \\
\hline
\end{tabular}


Figure 1: Reported time (in minutes) that respondents thought children should play outdoors 